Supporting Information

\title{
Heavy-Water Enables High-Voltage Aqueous Electrochemistry via the Deuterium Isotope Effect
}

Shengying Cai, Tianwen Bai, Hao Chen,* Wenzhang Fang, Zhen Xu,* Haiwen Lai, Tieqi Huang, Hanyan Xu, Xingyuan Chu, Jun Ling, ${ }^{*}$ and Chao Gao*

MOE Key Laboratory of Macromolecular Synthesis and Functionnalization, Department of Polymer Science and Engineering, Key Laboratory of Adsorption and Separation Materials \& Technologies of Zhejiang Province, Zhejiang University, Hangzhou 310027, P. R. China 


\section{Materials.}

Lithium sulfate (anhydrous, $99.9 \%$ ), sodium sulfate (anhydrous, $\geq 99.0 \%$ ), potassium sulfate (AR, $99 \%$ ), lithium bis(trifluoromethane sulfonyl)imide and deuterium oxide (99 atom \% D) were purchased from Shanghai Aladdin Bio-Chem Technology Co., Ltd. Sulfuric acid (GR, 95.0 98.0\%), potassium hydroxide (GR, $\geq 85.0 \%$ ) and ammonium bicarbonate (AR, $99 \%$ ) were purchased from Sinopharm Chemical Reagent Co., Ltd. Graphene oxide with average lateral size of $20 \mu \mathrm{m}$ was acquired from GaoxiTech Co., Ltd. All reagents were used as received without any further treatment. Deionized water was generated by PW Ultra-pure Water System and had a resistivity of $18 \mathrm{M} \Omega \mathrm{cm}$.

\section{Equations.}

The overall $\Delta \mathrm{G}$ of hydrogen and oxygen evolution is respectively described by Eq. 1 and 2, where $\mathrm{G}_{s}, \mathrm{H}_{2} \mathrm{O}$ represents the hydration energy between electrolyte ions and water molecule, $\Phi_{M}$ indicates the electronic work function of electrode $M, E_{H}$ and $E_{O}$ denotes the activation energy of hydrogen and hydroxyl ions in the gas phase to take part in corresponding redox reactions.

$$
\begin{aligned}
& \Delta G=-G_{s, H_{2} O}+\phi_{M}+\left(-E_{H}\right) \quad \text { Eq. S1 } \\
& \Delta G=-G_{s, H_{2} O}+\left(-\phi_{M}\right)+\left(-E_{O}\right) \quad \text { Eq. S2 }
\end{aligned}
$$

When heavy water is used to prepare electrolytes, expanding ratios $R_{D}$ (\%) of potential window is calculated by Eq. 3, where $U_{D}$ represents the potential limit of electrolyte dissolved in heavy water and $U_{H}$ indicates the potential limit of electrolyte prepared by light water.

$$
R_{D}=\frac{\left(\left|U_{D}\right|-\left|U_{H}\right|\right)}{\left|U_{H}\right|} \times 100 \% \quad \text { Eq. S3 }
$$

Hydration difference between heavy water and light water is obtained by Eq. 4, where $(E+Z P C)_{\mathrm{D}_{2} \mathrm{O}}$ and $(E+Z P C)_{\mathrm{H}_{2} \mathrm{O}}$ denote the zero point vibration energy of $\mathrm{D}_{2} \mathrm{O}$ and $\mathrm{H}_{2} \mathrm{O}$ predicted by DFT simulations.

$$
\Delta(E+Z P C)=(E+Z P C)_{D_{2} \mathrm{O}}-(E+Z P C)_{\mathrm{H}_{2} \mathrm{O}} \quad \text { Eq. S4 }
$$

The basic kinetic equation for hydrogen evolution process can be described by Eq. 5, where $\theta_{H}$ is the coverage of electrode surface by $H$, and $k$ is a rate constant for the process at a hypothetical $\mathrm{V}=0 . \mathrm{C}_{\mathrm{H}^{+}}$is the local concentration of reacting $\mathrm{H}^{+}$ion at electrode surface in the Helmholtz compact-layer region of the double layer.

$i=z F k c_{H^{+}}\left(1-\theta_{H}\right) \exp -[\beta V F /(R T)] \quad$ Eq. S5

In the case of an electrochemical capacitor being over charged, current response I is divided into two different components as Eq. 6 shows, where $\mathrm{I}_{\mathrm{C}}$ represents the charging current and $I_{F}$ indicates the Faradaic leakage current which is resulted by water splitting. 
$I=I_{C}+I_{F} \quad$ Eq. S6

The diffusion-controlled faradaic part ascribed to hydrogen and oxygen evolutions is quantified by Eq. 7, where $i(V)$ represents the current response at a fixed potential $V, v$ is scan rate, $k_{1} v$ indicates the current component originated from capacitive effects and $\mathrm{k}_{2} \mathrm{v}^{1 / 2}$ denotes the one resulted by diffusion-controlled reactions.

$i(V)=k_{1} v+k_{2} v^{1 / 2} \quad$ Eq. S7

The gravimetric specific capacitance $\mathrm{C}_{\mathrm{s}}\left(\mathrm{F} \mathrm{g}^{-1}\right)$ obtained from $\mathrm{CV}$ result was calculated by Eq. 8, where I (A) represents the instant current of CV curves, $v\left(\mathrm{~V} \mathrm{~s}^{-1}\right)$ indicates scan rate, $\Delta \mathrm{U}(\mathrm{V})$ stands for the potential window and $\mathrm{m}(\mathrm{g})$ is the weight of single electrode.

$C_{S}=\frac{\oint I d U}{m \times v \times(\Delta U)} \quad$ Eq. S8

The gravimetric specific capacitance $C_{s}\left(F^{-1}\right)$ obtained from GCD result was calculated by Eq. 9, where I (A) represents the discharge current, $t(s)$ indicates discharge time, $\Delta U(V)$ stands for the potential window and $\mathrm{m}(\mathrm{g})$ is the weight of single electrode.

$C_{S}=\frac{2 \times I \times t}{m \times \Delta U} \quad$ Eq. S9

The coulombic efficiency CE (\%) was calculated by Eq. 10 , where $C_{\text {disc }}$ represents the discharging capacity of $\mathrm{SC}$ and $\mathrm{C}_{\mathrm{c}}(\mathrm{s})$ indicates the charging capacity.

$C E=\frac{C_{\text {disc }}}{C_{c}} \times 100 \% \quad$ Eq. S10

\section{Preparation of electrolyte solutions.}

Calculated amount of electrolytes were respectively transferred to $20 \mathrm{~mL}$ glass bottles. Natural light water, deuterium oxide and their mixtures with different ratios were added as the solvent by syringes. After complete dissolution, these electrolyte solutions were sealed and preserved for electrochemical tests. All operations were carried out at atmospheric environment.

\section{Preparation of graphene hydrogel film.}

Ammonium bicarbonate cross-linked GO hydrogel film was firstly prepared by wet-spun technology and 10 wt \% ammonium bicarbonate aqueous solution was used as the coagulation bath. The obtained GO hydrogel film was subsequently transferred into a autoclave containing $70 \mathrm{~mL}$ of coagulation bath and heated to $180{ }^{\circ} \mathrm{C}$ for 2 hours. The resulted GHF was washed by deionized water several times and preserved in water.

\section{Preparation of highly graphitized graphene film.}

Highly graphitized graphene film (GF) was obtained by previously reported method. Firstly, graphene oxide (GO) film was prepared via scraping GO suspension (10-20 $\mathrm{mg} \mathrm{mL}^{-}$ 
$\left.{ }^{1}\right)$ on a copper foil by Long Tape Casting Coater (MSK-AFA-L800). After evaporation of water at room temperature, the $\mathrm{GO}$ film was then carbonized at $1300{ }^{\circ} \mathrm{C}$ for 2 hours and $3000{ }^{\circ} \mathrm{C}$ for 1 hour in a graphite furnace which was under the protection of argon flow to remove oxygen-containing groups and restore defects. The GF was used as working electrode in three-electrode tests and current collectors in supercapacitors.

\section{Electrochemical measurements.}

In the three-electrode system, GF, graphite rod and $\mathrm{Ag} / \mathrm{AgCl}$ electrode were used as working, counter and reference electrodes, respectively. The linear sweep voltammetry was performed from $0 \mathrm{~V}$ versus $\mathrm{Ag} / \mathrm{AgCl}$ to positive and negative limits at a relatively slow scan rate of $10 \mathrm{mV} \mathrm{s}^{-1}$ on $\mathrm{CHI} 660 \mathrm{E}$ (CH Instruments, Inc., Shanghai, China) and a value of $0.5 \mathrm{~mA} \mathrm{~cm}{ }^{-2}$ was defined as the threshold for electrolyte decomposition. Before formal tests, each electrolyte solution was firstly tested at least 10 times to reach a stable state. As for two-electrode system, symmetric supercapacitor assembled in a custom-made swagelok device was used for characterization. In order to avoid the direct contact between electrolyte with iron rod, parafilm and PI tape was used to coat the iron rods (Figure S11C and D). Electrodes were separated by a non-woven fabric (thickness of $100 \mu \mathrm{m}$, MPF30AC, Nippon Kodoshi Corp., Japan) and GF (1.0 cm in diameter) was used as the current collector. GHF $\left(0.15 \mathrm{mg}\right.$, mass loading of $\left.0.26 \mathrm{mg} \mathrm{cm}{ }^{-2}\right)$ was firstly transferred to electrolyte solutions to exchange the water in hydrogel film before tests. Cyclic voltammetry and galvanostatic charge/discharge tests were measured on $\mathrm{CHI} 660 \mathrm{E}$ and results were obtained after the first several cycles. Electrochemical impedance spectroscopy (EIS) was performed on Multi Autolab M204 (Metrohm). A programmable fast thermal test chamber (MSK-TE906) was used to control the temperature of SCs. The long term tests were carried out on a Land BT2000 battery test system.

\section{DFT calculation of hydration energy.}

All geometries of intermediates were optimized using B3LYP/6-31G(d,p) method under tight criteria with DFT-D3 correction. Frequency calculations confirmed that the intermediates had zero imaginary frequency. Thermal correction to Gibbs free energies was obtained at $298.2 \mathrm{~K}$ and $1.013 \times 105 \mathrm{~Pa}$. All calculations were performed using Gaussian 16 program. In molecular scale, dilute and concentrated solution was recognized as different number of coordinated solvent molecules. Saturated hydration shell is employed to represent dilute solutions for alkali ions. According to DFT calculation results, larger hydration energy difference was found with increasing number of coordinated $\mathrm{H}_{2} \mathrm{O} / \mathrm{D}_{2} \mathrm{O}$ for lithium ion. When larger radius of alkali ion was carried out, larger interaction difference between $\mathrm{H}_{2} \mathrm{O} / \mathrm{D}_{2} \mathrm{O}$ was observed due to increasing of coordinated number.

\section{Nuclear Magnetic Resonance spectra.}

$1 \mathrm{H}$ NMR spectra of $0.5 \mathrm{~m} \mathrm{Li}_{2} \mathrm{SO}_{4}, 0.5 \mathrm{~m} \mathrm{Na}_{2} \mathrm{SO}_{4}, 0.5 \mathrm{~m} \mathrm{~K}_{2} \mathrm{SO}_{4}, 1 \mathrm{~m}$ LiTFSI, $5 \mathrm{~m}$ LiTFSI, $10 \mathrm{~m}$ LiTFSI, $15 \mathrm{~m}$ LiTFSI and $21 \mathrm{~m}$ LiTFSI were obtained on a Brulcer $500 \mathrm{MHz} \mathrm{NMR}$ spectrometer (DMX-500). Typically, $0.5 \mathrm{~mL}$ of electrolyte aqueous solution was added to a $5 \mathrm{~mm}$ glass NMR tube for characterization and chloroform-d $\left(\mathrm{CDCl}_{3}\right)$ in a sealed coaxial glass tube was used for reference. Data were processed in MestReNova 11.0.4. 


\section{Raman spectra.}

Raman tests of $1 \mathrm{~m}$ LiTFSI, 5m LiTFSI, 10m LiTFSI, 15m LiTFSI and $21 \mathrm{~m}$ LiTFSI aqueous solutions were carried out on inVia-Reflex (Renishaw plc).

\section{Scanning Electron Microscopy measurement.}

SEM measurements of freeze dried graphene hydrogel film were performed on a Hitachi S-4800 at an operating voltage of $3.0 \mathrm{kV}$.

\section{X-ray Photoelectron Spectroscopy.}

XPS measurement of graphene hydrogen film was carried out on a PHI 5000C ESCA system (Physical Electronics) operated at $14.0 \mathrm{kV}$. 


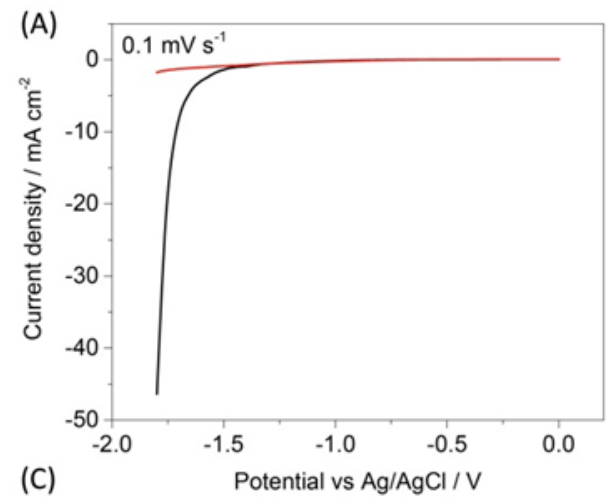

(C)

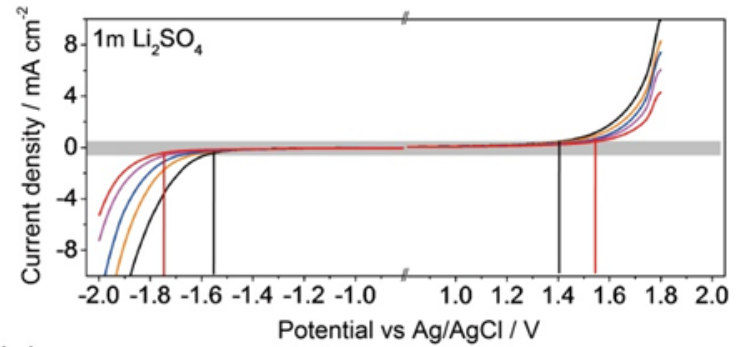

(D)

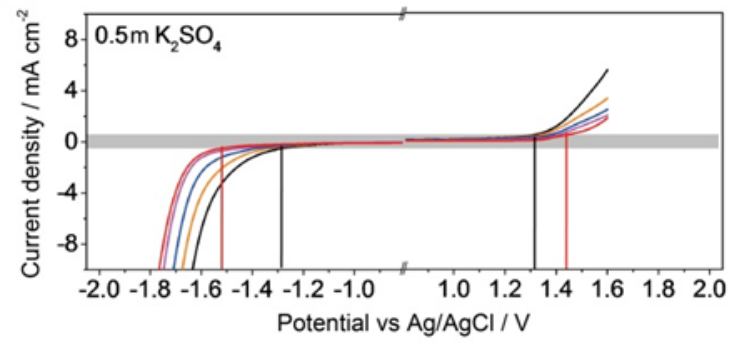

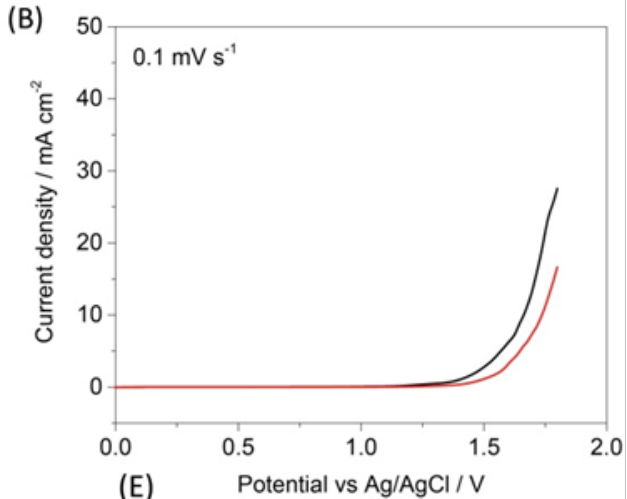

(E)

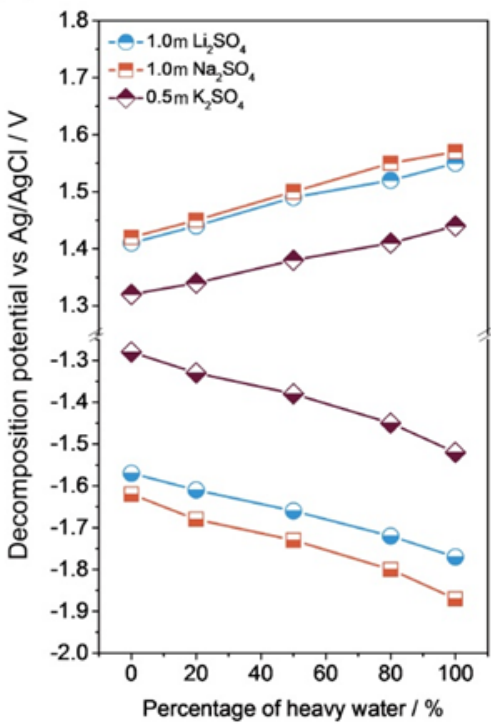

Figure S1 (A) Hydrogen and (B) oxygen evolution curves of $1 \mathrm{~m} \mathrm{Na}_{2} \mathrm{SO}_{4}$ aqueous solution at a scan rate as low as $0.1 \mathrm{mV} \mathrm{s}^{-1}$. The red line represents electrolyte prepared by heavy water while the black line represents the one prepared by natural water. (C and D), LSV curves of $1 \mathrm{~m} \mathrm{Li}_{2} \mathrm{SO}_{4}$ and $0.5 \mathrm{~m} \mathrm{~K}{ }_{2} \mathrm{SO}_{4}$ aqueous solutions prepared by water with $0 \%, 20 \%, 50 \%, 80 \%$ and $100 \%$ contents of heavy water. (E) Decomposition potentials of sulfate aqueous solutions with different contents of heavy water. All of the LSV tests in c-e were performed at a scan rate of $10 \mathrm{mV} \mathrm{s}^{-1}$ on GF electrode and the current density of 0.5 $\mathrm{mA} \mathrm{cm}{ }^{-2}$ was defined as the threshold for electrolyte decomposition. 

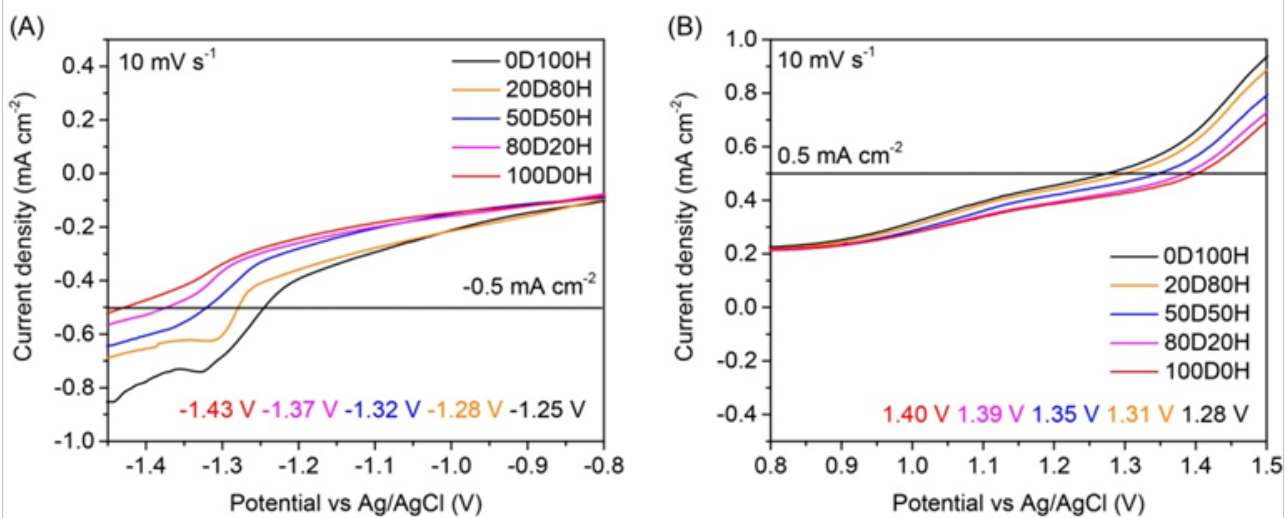

Figure S2 (A) Hydrogen and (B) oxygen evolution curves of $0.5 \mathrm{~m} \mathrm{Na}{ }_{2} \mathrm{SO}_{4}$ aqueous solution at a scan rate of $10 \mathrm{mV} \mathrm{s}^{-1}$ on GF electrode and the current density of $0.5 \mathrm{~mA} \mathrm{~cm}^{-2}$ was defined as the threshold for electrolyte decomposition. 
(A)

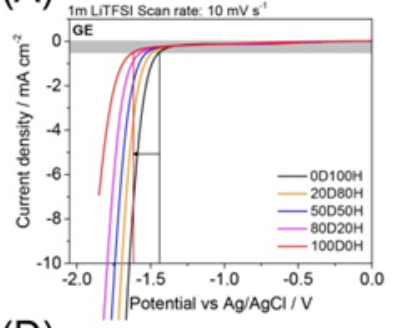

(D)

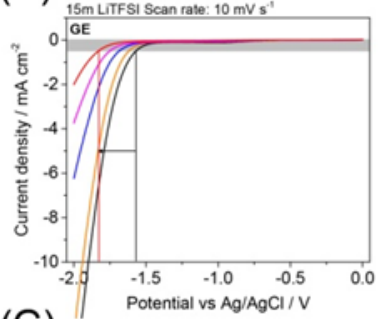

(G)

(B)

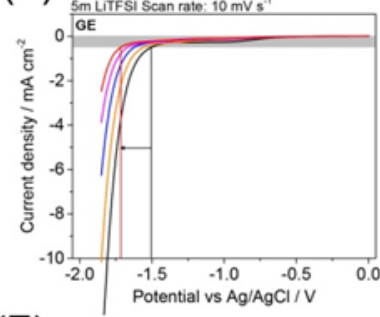

(E)

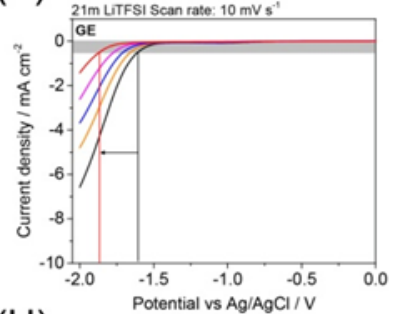

(H)

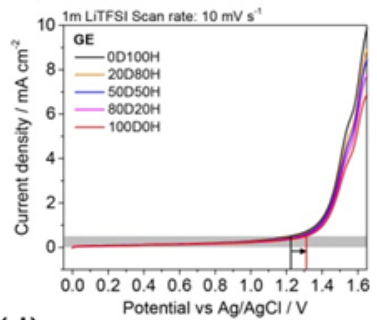

(J)

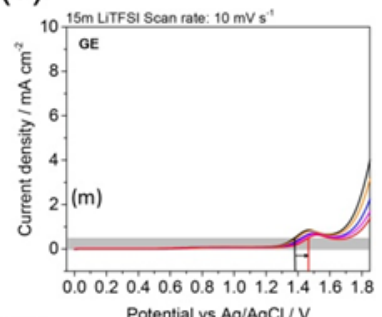

(M)

(M)

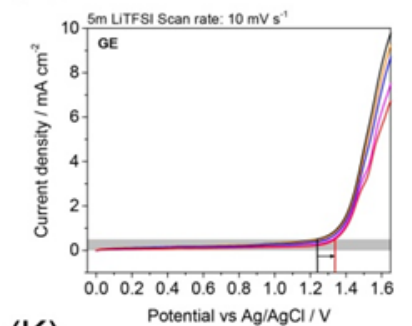

(K)

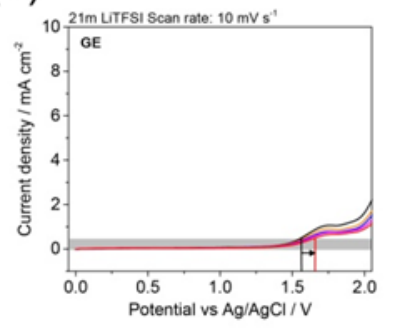

Potential vs Ag/2 1.4
(C)

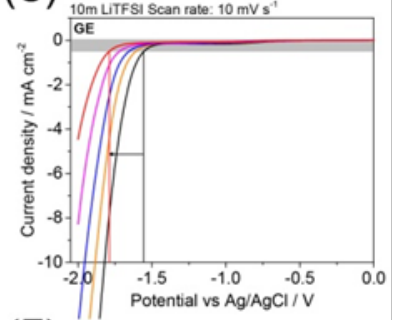

(F)

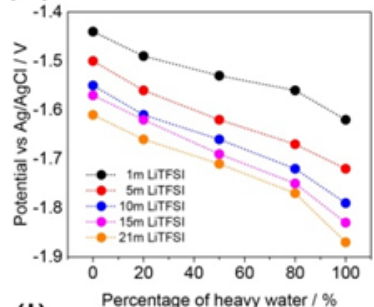

(I)

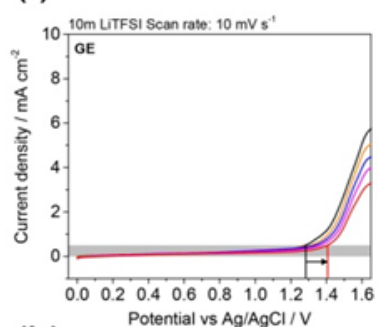

(L)

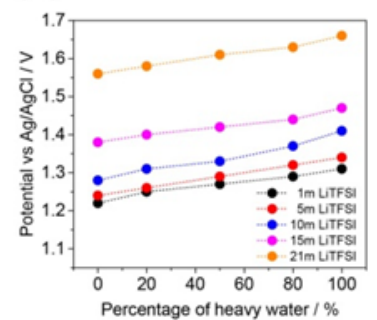

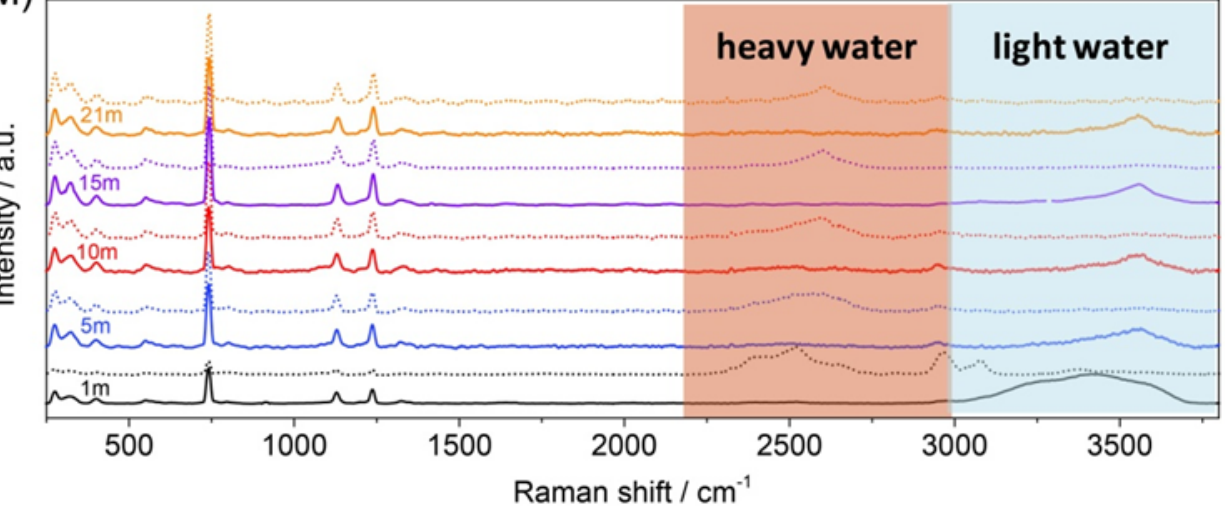

Figure S3 (A-E), Negative LSV curves of 1-21m LiTFSI aqueous solutions with $0 \%, 20 \%, 50 \%, 80 \%$ and $100 \%$ contents of heavy water. (F) Hydrogen evolution potentials of LiTFSI aqueous solutions with increasing contents of heavy water. (G-L), Positive LSV curves of $1-21 \mathrm{~m}$ LiTFSI aqueous solutions with $0 \%, 20 \%, 50 \%$, $80 \%$ and $100 \%$ contents of heavy water. (L) Oxygen evolution potentials of LiTFSI aqueous solutions with increasing contents of heavy water. All of the LSV tests were performed at a scan rate of $10 \mathrm{mV} \mathrm{s}^{-1}$ on GF electrode and the current density of $0.5 \mathrm{~mA} \mathrm{~cm}^{-2}$ was defined as the threshold for electrolyte decomposition. (M) Raman spectra of LiTFSI aqueous solutions prepared by heavy water (dot line) and natural water (solid line) respectively. 

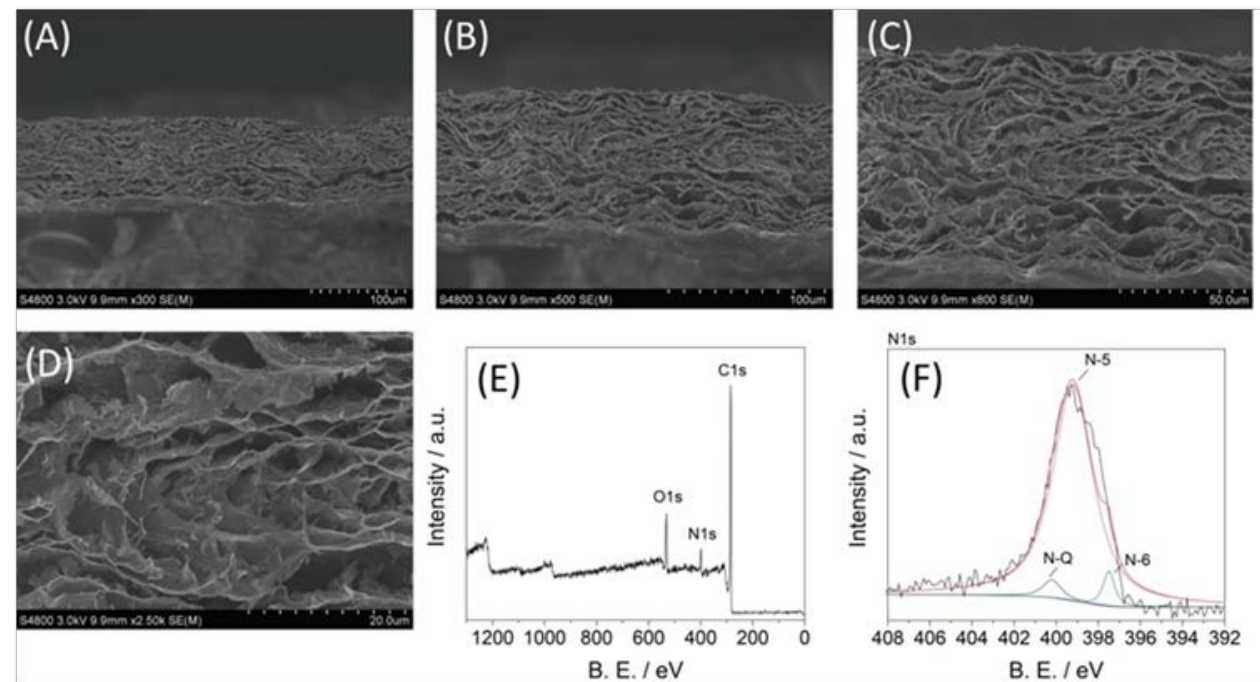

Figure S4 (A-D) SEM photos of freeze-dried GHF with different magnifications. (E) and (F), X-ray photoelectron spectroscopy (XPS) spectrum of freeze-dried GHF. 

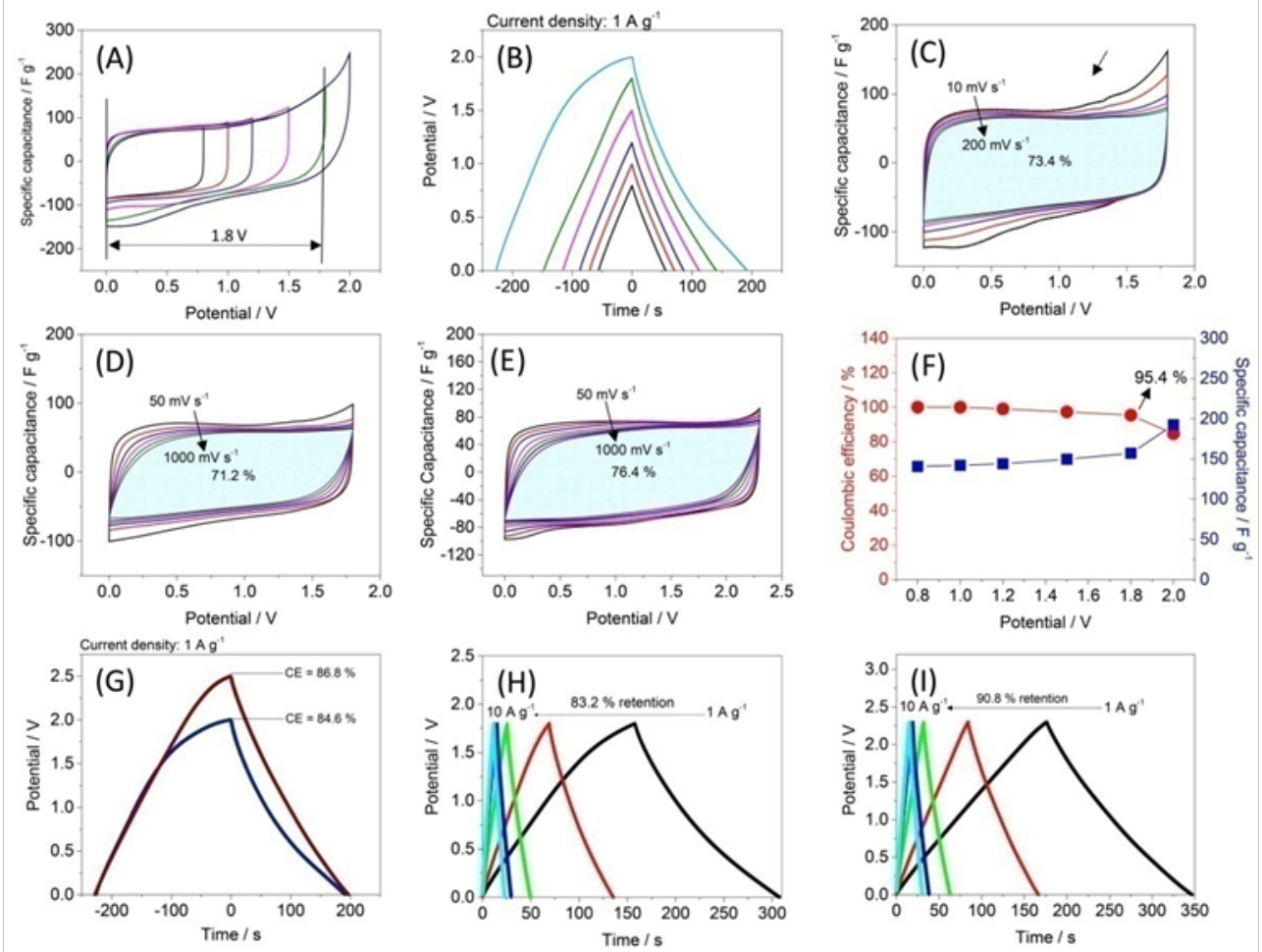

Figure S5 (A) CV curves of GHF-assembled SC using $\mathrm{H}_{2} \mathrm{O}\left(1 \mathrm{~m} \mathrm{Na} \mathrm{SO}_{4}\right)$ as the electrolyte. The potential window was increased from 0.8 to $2.0 \mathrm{~V}$ at a scan rate of $10 \mathrm{mV} \mathrm{s}^{-1}$. (B) GCD curves of $\mathrm{SC}-\mathrm{H}_{2} \mathrm{O}\left(1 \mathrm{~m} \mathrm{Na}_{2} \mathrm{SO}_{4}\right)$ at $1 \mathrm{~A} \mathrm{~g}^{-1}$, in which the potential window was increased from 0.8 to $2.0 \mathrm{~V}$. (C) CV curves of a $1.8 \mathrm{~V}-\mathrm{SC}-\mathrm{H}_{2} \mathrm{O}$ $\left(1 \mathrm{~m} \mathrm{Na}_{2} \mathrm{SO}_{4}\right)$ at $10-200 \mathrm{mV} \mathrm{s}^{-1}$. (D) CV curves of a $1.8 \mathrm{~V}-\mathrm{SC}^{-} \mathrm{H}_{2} \mathrm{O}\left(1 \mathrm{~m} \mathrm{Na}_{2} \mathrm{SO}_{4}\right)$ at $50-1000 \mathrm{mV} \mathrm{s}^{-1}$. (E) CV curves of a 2.3V-SC- $\mathrm{D}_{2} \mathrm{O}\left(1 \mathrm{~m} \mathrm{Na}_{2} \mathrm{SO}_{4}\right)$ at 50 to $1000 \mathrm{mV} \mathrm{s}^{-1}$. (F) Specific capacitance and coulombic efficiency of SC- $\mathrm{H}_{2} \mathrm{O}\left(1 \mathrm{~m} \mathrm{Na}_{2} \mathrm{SO}_{4}\right)$ at $1 \mathrm{~A} \mathrm{~g}^{-1}$. (G) GCD curves of a 2.5V-SC- $\mathrm{D}_{2} \mathrm{O}\left(1 \mathrm{~m} \mathrm{Na}_{2} \mathrm{SO}_{4}\right)$ (red) and a $2.0 \mathrm{~V}-\mathrm{SC}-\mathrm{H}_{2} \mathrm{O}\left(1 \mathrm{~m} \mathrm{Na}_{2} \mathrm{SO}_{4}\right)$ (blue) at $1 \mathrm{~A} \mathrm{~g}^{-1}$. (H) Rate capability of a $1.8 \mathrm{~V}-\mathrm{SC}-\mathrm{H}_{2} \mathrm{O}\left(1 \mathrm{~m} \mathrm{Na}{ }_{2} \mathrm{SO}_{4}\right)$, where the current density is increased from 1 to $10 \mathrm{~A} \mathrm{~g}^{-1}$. (I) Rate capability of a 2.3V-SC- $\mathrm{D}_{2} \mathrm{O}\left(1 \mathrm{~m} \mathrm{Na}_{2} \mathrm{SO}_{4}\right)$, where the current density is increased from 1 to $10 \mathrm{~A} \mathrm{~g}^{-1}$. 

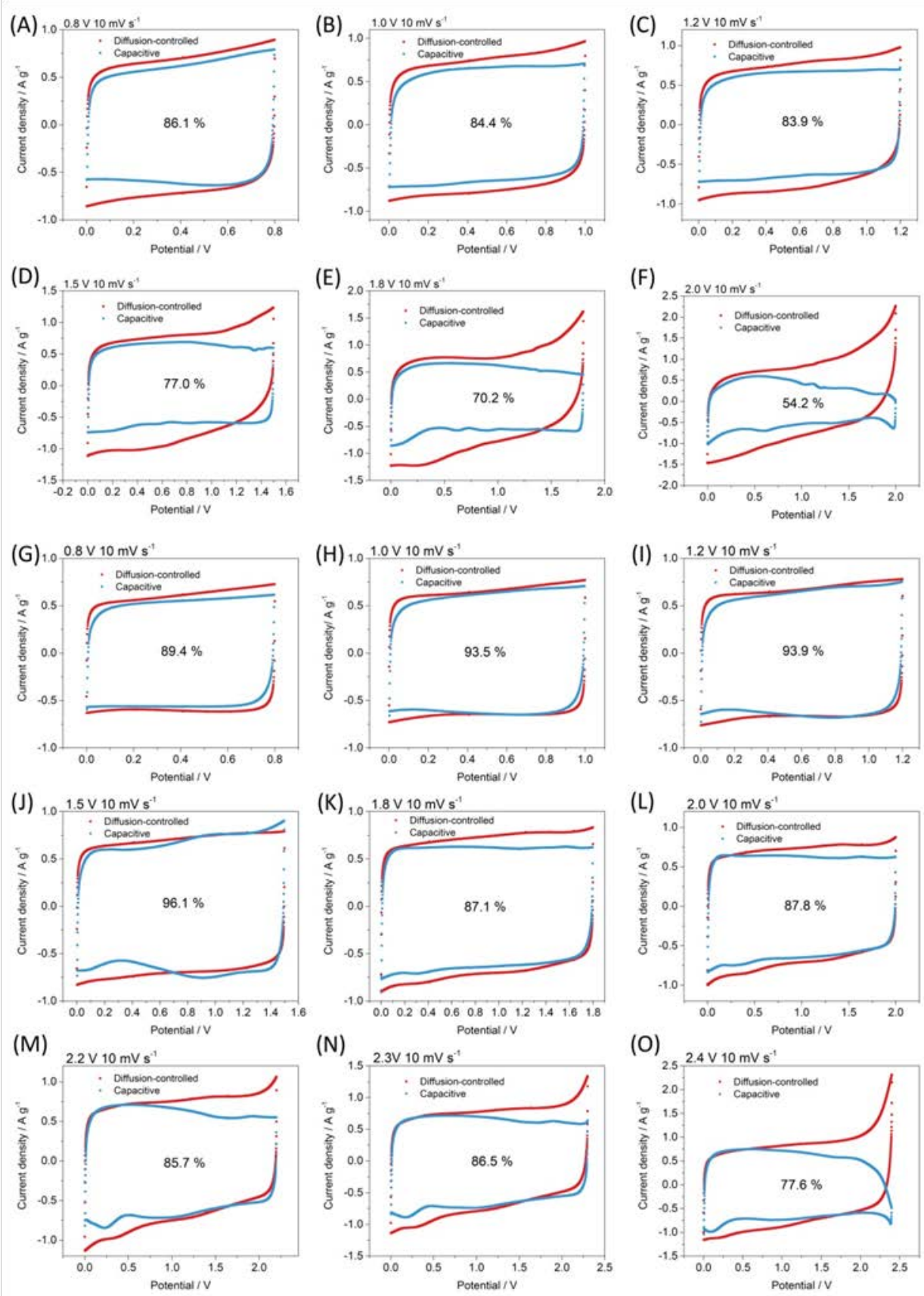

(0)

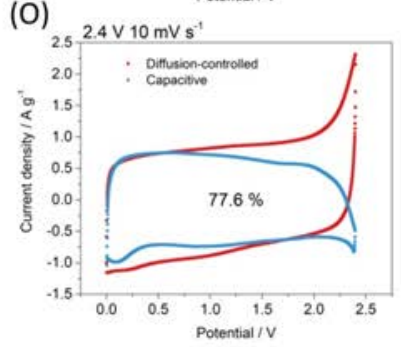

Figure S6 (A-F) CV curves of SCs using $1 \mathrm{~m} \mathrm{Na}_{2} \mathrm{SO}_{4}-\mathrm{H}_{2} \mathrm{O}$ electrolyte. (G-O) CV curves of SCs using $1 \mathrm{~m}$ $\mathrm{Na}_{2} \mathrm{SO}_{4}-\mathrm{D}_{2} \mathrm{O}$ electrolyte. Area enclosed by blue lines represents the capacitive contributions calculated by Eq. 7. 


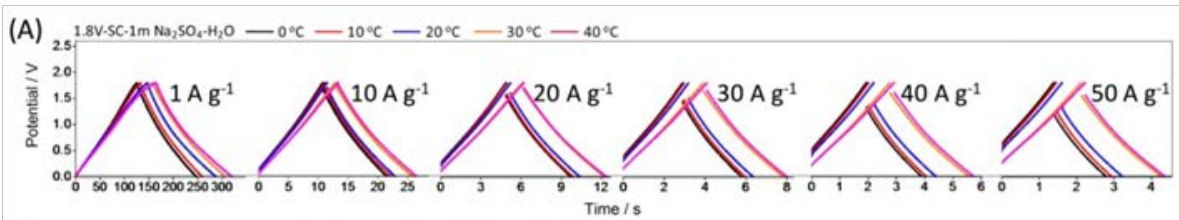

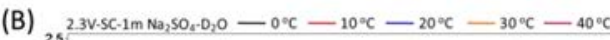
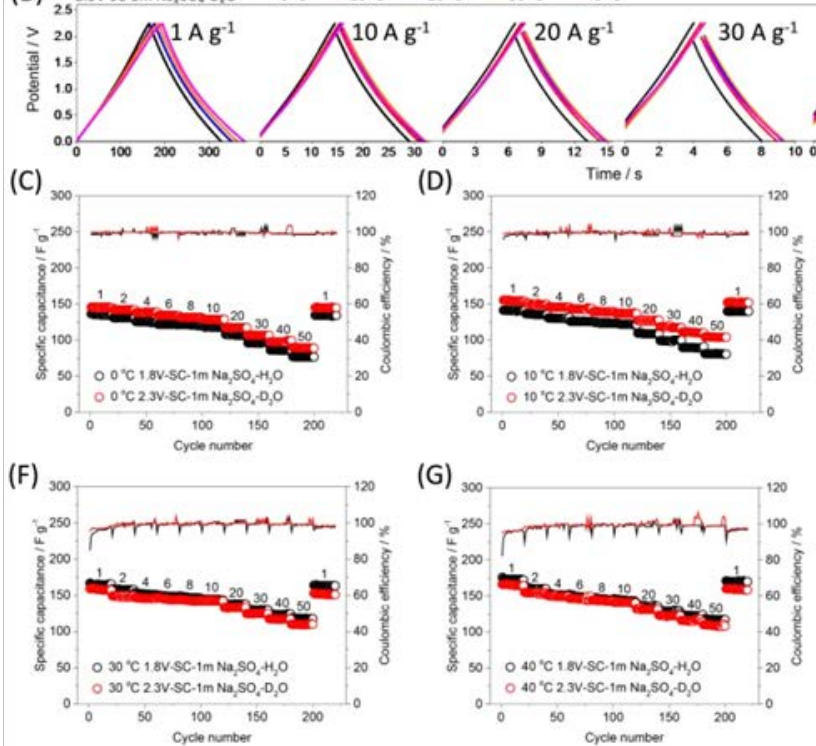

(G)
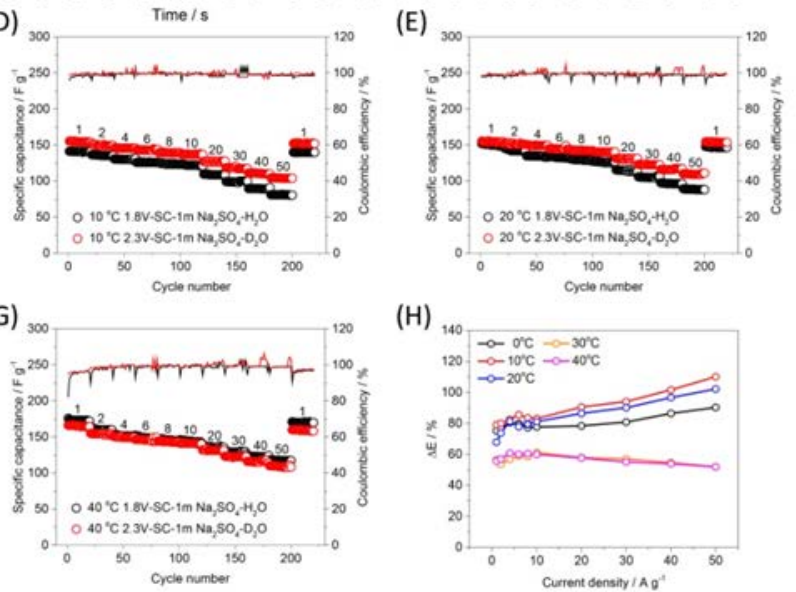

Figure S7 GCD curves of (A) $1.8 \mathrm{~V}-\mathrm{SC}-\mathrm{H}_{2} \mathrm{O}\left(1 \mathrm{~m} \mathrm{Na}_{2} \mathrm{SO}_{4}\right)$ and (B) $2.3 \mathrm{~V}-\mathrm{SC}-\mathrm{D}_{2} \mathrm{O}\left(1 \mathrm{~m} \mathrm{Na} \mathrm{SO}_{4}\right)$ with increasing current densities, at the temperature of 0-40 ${ }^{\circ} \mathrm{C}$. C-G, Specific capacitance (dot) and corresponding coulombic efficiency (line) of $1.8 \mathrm{~V}-\mathrm{SC}-\mathrm{H}_{2} \mathrm{O}\left(1 \mathrm{~m} \mathrm{Na}_{2} \mathrm{SO}_{4}\right)$ and $2.3 \mathrm{~V}-\mathrm{SC}-\mathrm{D}_{2} \mathrm{O}\left(1 \mathrm{~m} \mathrm{Na}_{2} \mathrm{SO}_{4}\right)$ at (C) $0{ }^{\circ} \mathrm{C}$, (D) $10^{\circ} \mathrm{C}$, (E) $20^{\circ} \mathrm{C}$, (F) $30{ }^{\circ} \mathrm{C}$, and (G) $40^{\circ} \mathrm{C}$. The current density in $\mathrm{C}-\mathrm{G}$ is increased from 1 to $50 \mathrm{~A} \mathrm{~g}^{-1}$ and is denoted by the numbers above dots. $(\mathrm{H}) \Delta \mathrm{E}$ of $2.3 \mathrm{~V}-\mathrm{SC}-\mathrm{D}_{2} \mathrm{O}\left(1 \mathrm{~m} \mathrm{Na} \mathrm{SO}_{4}\right)$ at different temperatures, where $\Delta \mathrm{E}$ denotes the increment of energy density compared with $1.8 \mathrm{~V}-\mathrm{SC}$ which use $\mathrm{H}_{2} \mathrm{O}\left(1 \mathrm{~m} \mathrm{Na} \mathrm{SO}_{4}\right)$ as the electrolyte. 
(A)

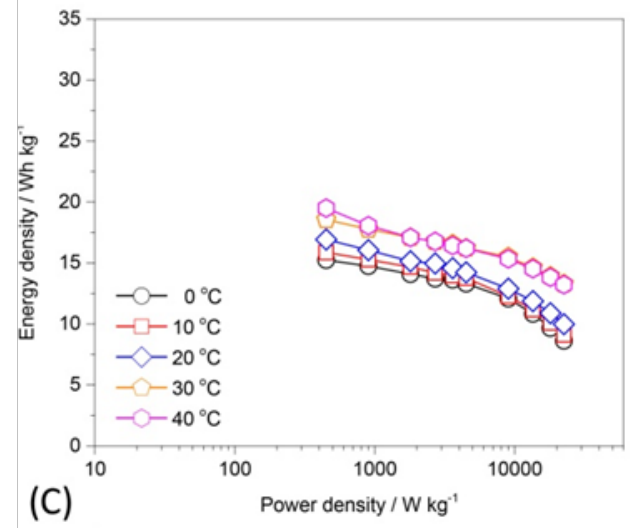

(B)

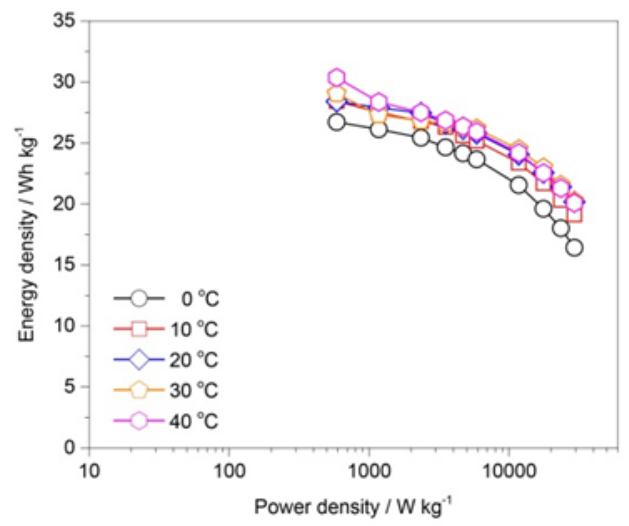

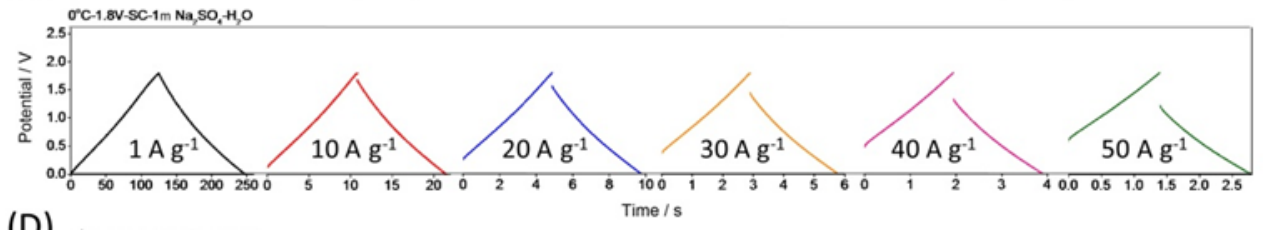

(D) Time/s

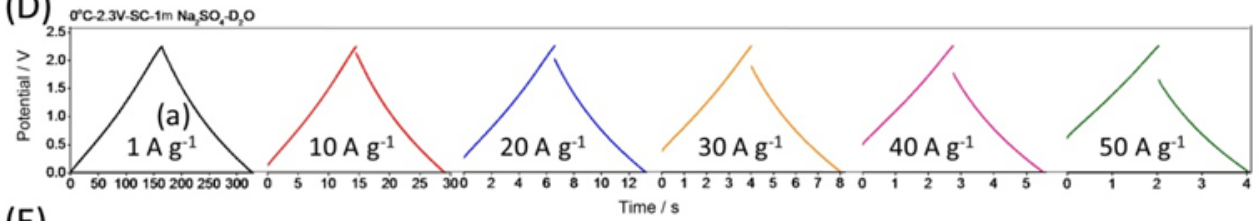

(E) Time/s

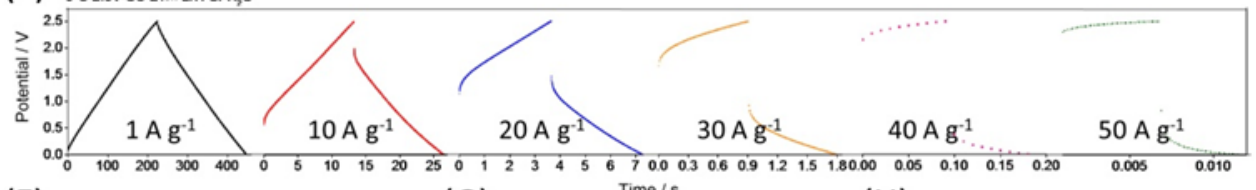

(F)

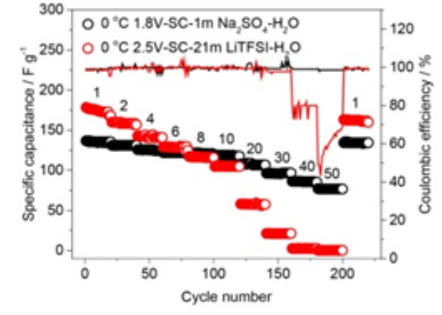

(G)

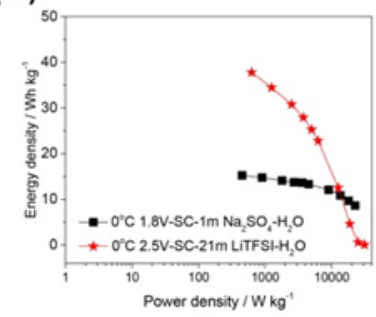

$(\mathrm{H})$

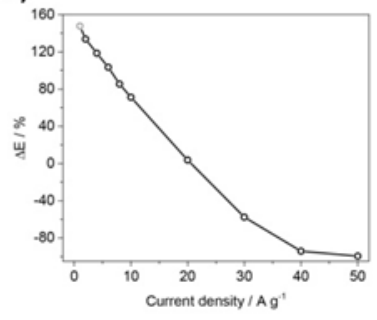

Figure S8 (A) Ragone plots of $1.8 \mathrm{~V}-\mathrm{SC}-\mathrm{H}_{2} \mathrm{O}\left(1 \mathrm{~m} \mathrm{Na}_{2} \mathrm{SO}_{4}\right)$ and (B) $2.3 \mathrm{~V}-\mathrm{SC}-\mathrm{D}_{2} \mathrm{O}\left(1 \mathrm{~m} \mathrm{Na} \mathrm{SO}_{4}\right)$ at the temperature of $0-40{ }^{\circ} \mathrm{C}$. (C-E) GCD curves of (C) $1.8 \mathrm{~V}-\mathrm{SC}-\mathrm{H}_{2} \mathrm{O}\left(1 \mathrm{~m} \mathrm{Na}{ }_{2} \mathrm{SO}_{4}\right)$, (D) $2.3 \mathrm{~V}-\mathrm{SC}-\mathrm{D}_{2} \mathrm{O}\left(1 \mathrm{~m} \mathrm{Na} \mathrm{SO}_{4}\right)$ and (E) 2.5V-SC- $\mathrm{H}_{2} \mathrm{O}(21 \mathrm{~m}$ LiTFSI) with the current density being continuously increased, at the temperature of $0{ }^{\circ} \mathrm{C}$. (F) Rate capability of $1.8 \mathrm{~V}-\mathrm{SC}-\mathrm{H}_{2} \mathrm{O}\left(1 \mathrm{~m} \mathrm{Na}{ }_{2} \mathrm{SO}_{4}\right)$ and $2.5 \mathrm{~V}-\mathrm{SC}-\mathrm{H}_{2} \mathrm{O}(21 \mathrm{~m} \mathrm{LiTFSI})$ at $0{ }^{\circ} \mathrm{C}$, where the current density was increased from 1 to $50 \mathrm{~A} \mathrm{~g}^{-1}$ and is denoted by the numbers above dots. Lines in $\mathrm{f}$ indicates the corresponding coulombic efficiency of SCs. (G) Ragone plots of $1.8 \mathrm{~V}-\mathrm{SC}-\mathrm{H}_{2} \mathrm{O}(1 \mathrm{~m}$ $\left.\mathrm{Na}_{2} \mathrm{SO}_{4}\right)$ and $2.5 \mathrm{~V}-\mathrm{SC}-\mathrm{H}_{2} \mathrm{O}(21 \mathrm{~m} \mathrm{LiTFSI})$ at $0{ }^{\circ} \mathrm{C}$. (H) $\Delta \mathrm{E}$ of $2.5 \mathrm{~V}-\mathrm{SC}-\mathrm{H}_{2} \mathrm{O}(21 \mathrm{~m} \mathrm{LiTFSI})$ at $0{ }^{\circ} \mathrm{C}$, where $\Delta \mathrm{E}$ denotes the increment of energy density compared with $1.8 \mathrm{~V}-\mathrm{SC}-\mathrm{H}_{2} \mathrm{O}\left(1 \mathrm{~m} \mathrm{Na}_{2} \mathrm{SO}_{4}\right)$. 

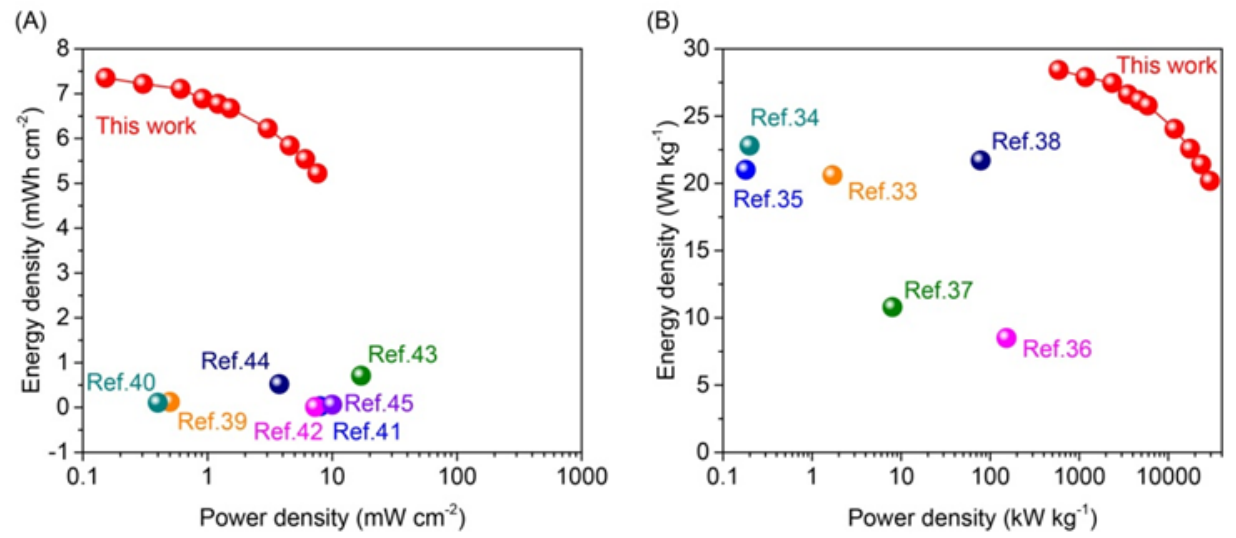

Figure S9 Ragone plots of 2.3V-SC- $\mathrm{D}_{2} \mathrm{O}\left(1 \mathrm{~m} \mathrm{Na}_{2} \mathrm{SO}_{4}\right)$ compared with other reported aqueous devices. (A) Mass specific energy density and power density. (B) Area specific energy density and power density. The energy density of our SCs are calculated by $E=0.125 \mathrm{CV}^{2} / 3.6$, where $\mathrm{C}$ is the specific capacitance of one electrode and $\mathrm{V}$ is the potential window. 
(A)
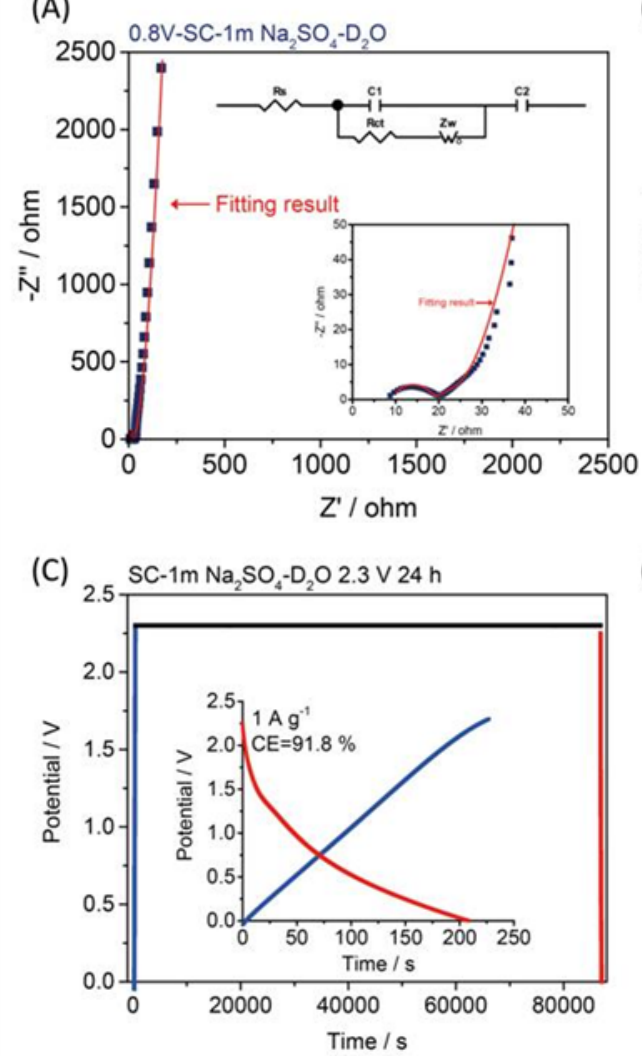

(B)

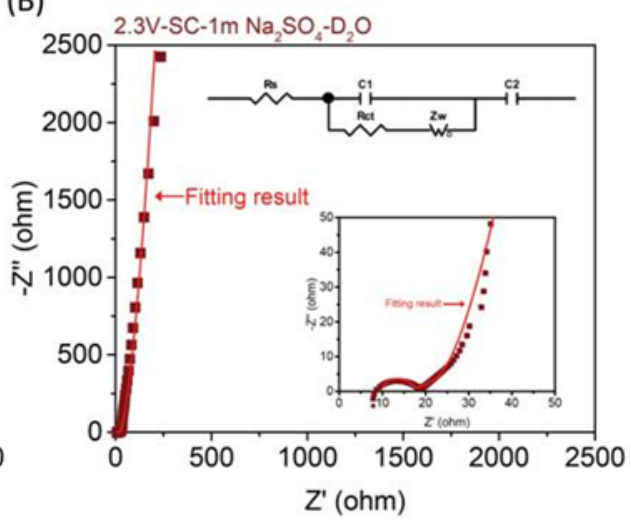

(D)

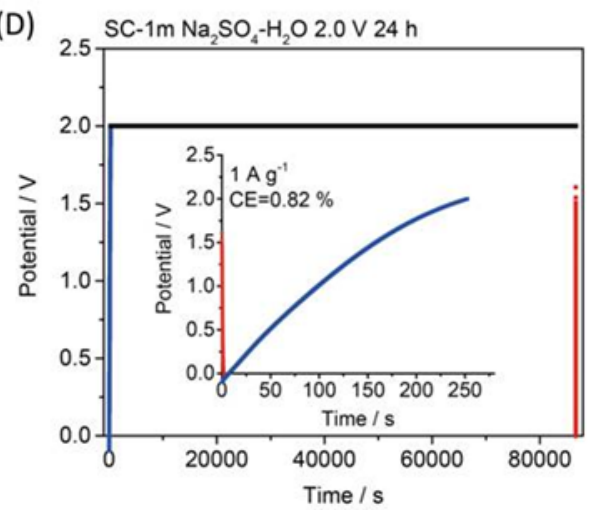

Figure $\mathrm{S} 10$ (A) EIS results of the SC- $\mathrm{D}_{2} \mathrm{O}\left(1 \mathrm{~m} \mathrm{Na}_{2} \mathrm{SO}_{4}\right)$ after GCD tests at $0.8 \mathrm{~V}$. (B) EIS results of the SC- $\mathrm{D}_{2} \mathrm{O}$ $\left(1 \mathrm{~m} \mathrm{Na}_{2} \mathrm{SO}_{4}\right)$ after $\mathrm{GCD}$ tests at $2.3 \mathrm{~V}$. Corresponding equivalent circuit diagram is showed in the insets. (C) The SC- $\mathrm{D}_{2} \mathrm{O}\left(1 \mathrm{~m} \mathrm{Na}_{2} \mathrm{SO}_{4}\right)$ was charged to $2.3 \mathrm{~V}$ at $1 \mathrm{~A} \mathrm{~g}^{-1}$ and then discharged at the same current density after it was kept at $2.3 \mathrm{~V}$ for $24 \mathrm{~h}$. (D) The $\mathrm{SC}-\mathrm{H}_{2} \mathrm{O}\left(1 \mathrm{~m} \mathrm{Na}_{2} \mathrm{SO}_{4}\right)$ was charged to $2.0 \mathrm{~V}$ at $1 \mathrm{~A} \mathrm{~g}^{-1}$ and then discharged at the same current density after it was kept at $2.0 \mathrm{~V}$ for $24 \mathrm{~h}$. Blue lines in the insets represent the charge processes and red lines represent the discharge processes. 

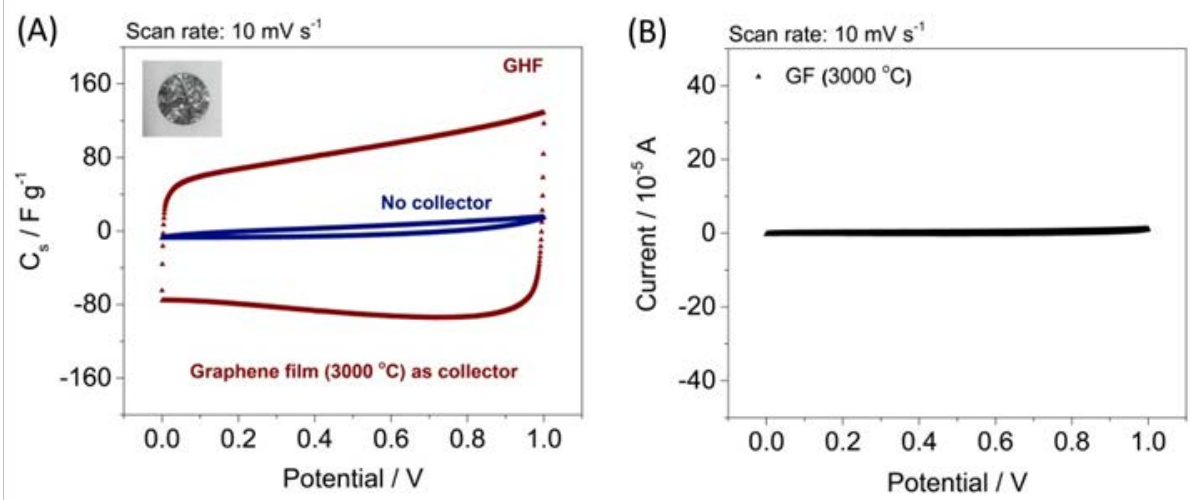

(C)

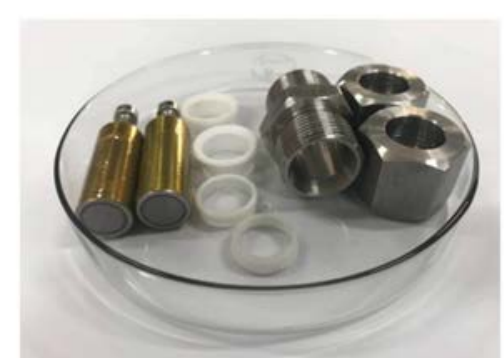

(D)

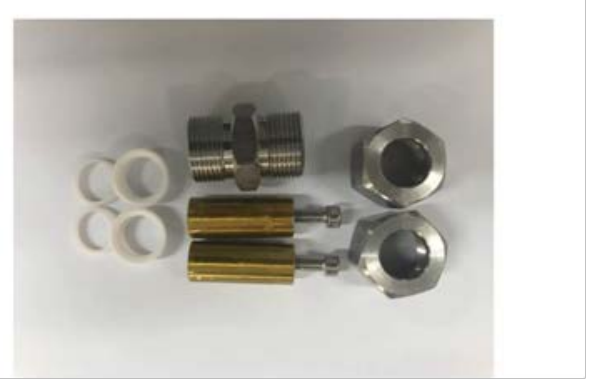

Figure S11 (A) CV curves of GHF-assembled SC with and without GF (inset in a) as the current collector. (B), $\mathrm{CV}$ curves of pure GF. The CV tests in A and B were performed at a scan rate of $10 \mathrm{mV} \mathrm{s}^{-1}$ by CHI 660E. (C and D) Optical photograph of a swagelok device coated by parafilm and PI tape. 
Table S1 Hydrogen evolution limits of electrolytes on $\mathrm{GF}$ (versus $\mathrm{Ag} / \mathrm{AgCl}$ )

\begin{tabular}{|c|c|c|c|c|}
\hline Electrolyte & Natural water & Heavy water & $\Delta \mathrm{U}$ & $\mathrm{FD}_{\mathrm{D}}$ \\
\hline $1 \mathrm{~m} \mathrm{Li}{ }_{2} \mathrm{SO}_{4}$ & $-1.57 \mathrm{~V}$ & $-1.77 \mathrm{~V}$ & $0.20 \mathrm{~V}$ & $12.7 \%$ \\
\hline $1 \mathrm{~m} \mathrm{Na}_{2} \mathrm{SO}_{4}$ & $-1.62 \mathrm{~V}$ & $-1.87 \mathrm{~V}$ & $0.25 \mathrm{~V}$ & $15.4 \%$ \\
\hline $0.5 \mathrm{~m} \mathrm{~K}_{2} \mathrm{SO}_{4}$ & $-1.28 \mathrm{~V}$ & $-1.52 \mathrm{~V}$ & $0.24 \mathrm{~V}$ & $18.8 \%$ \\
\hline $1 m$ LiTFSI & $-1.44 \mathrm{~V}$ & $-1.62 \mathrm{~V}$ & $0.18 \mathrm{~V}$ & $12.5 \%$ \\
\hline 5m LiTFSI & $-1.50 \mathrm{~V}$ & $-1.72 \mathrm{~V}$ & $0.22 \mathrm{~V}$ & $14.7 \%$ \\
\hline 10m LiTFSI & $-1.55 \mathrm{~V}$ & $-1.79 \mathrm{~V}$ & $0.24 \mathrm{~V}$ & $15.5 \%$ \\
\hline 15m LiTFSI & $-1.57 \mathrm{~V}$ & $-1.83 \mathrm{~V}$ & $0.26 \mathrm{~V}$ & $16.6 \%$ \\
\hline 21m LiTFSI & $-1.61 \mathrm{~V}$ & $-1.87 \mathrm{~V}$ & $0.26 \mathrm{~V}$ & $16.1 \%$ \\
\hline $1 \mathrm{~m} \mathrm{KOH}$ & $-1.22 \mathrm{~V}$ & $-1.43 \mathrm{~V}$ & $0.21 \mathrm{~V}$ & $17.2 \%$ \\
\hline $1 \mathrm{~m} \mathrm{H}_{2} \mathrm{SO}_{4}$ & $-0.97 \mathrm{~V}$ & $-1.12 \mathrm{~V}$ & $0.15 \mathrm{~V}$ & $15.5 \%$ \\
\hline Electrolyte & Natural water & Heavy water & $\Delta \mathrm{U}$ & $\mathrm{FD}_{\mathrm{D}}$ \\
\hline $1 \mathrm{~m} \mathrm{Li} 2 \mathrm{SO}_{4}$ & $1.41 \mathrm{~V}$ & $1.55 \mathrm{~V}$ & $0.14 \mathrm{~V}$ & $9.9 \%$ \\
\hline $1 \mathrm{~m} \mathrm{Na}_{2} \mathrm{SO}_{4}$ & $1.42 \mathrm{~V}$ & $1.57 \mathrm{~V}$ & $0.15 \mathrm{~V}$ & $10.6 \%$ \\
\hline $0.5 \mathrm{~m} \mathrm{~K}_{2} \mathrm{SO}_{4}$ & $1.32 \mathrm{~V}$ & $1.44 \mathrm{~V}$ & $0.12 \mathrm{~V}$ & $9.1 \%$ \\
\hline 1m LiTFSI & $1.22 \mathrm{~V}$ & $1.31 \mathrm{~V}$ & $0.09 \mathrm{~V}$ & $7.4 \%$ \\
\hline 5m LiTFSI & $1.24 \mathrm{~V}$ & $1.34 \mathrm{~V}$ & $0.10 \mathrm{~V}$ & $8.1 \%$ \\
\hline 10m LiTFSI & $1.28 \mathrm{~V}$ & $1.41 \mathrm{~V}$ & $0.13 \mathrm{~V}$ & $10.2 \%$ \\
\hline 15m LiTFSI & $1.38 \mathrm{~V}$ & $1.47 \mathrm{~V}$ & $0.09 \mathrm{~V}$ & $6.5 \%$ \\
\hline 21m LiTFSI & $1.56 \mathrm{~V}$ & $1.66 \mathrm{~V}$ & $0.10 \mathrm{~V}$ & $6.4 \%$ \\
\hline $1 \mathrm{~m} \mathrm{KOH}$ & $0.81 \mathrm{~V}$ & $0.91 \mathrm{~V}$ & $0.10 \mathrm{~V}$ & $12.3 \%$ \\
\hline $1 \mathrm{~m} \mathrm{H}_{2} \mathrm{SO}_{4}$ & $1.23 \mathrm{~V}$ & $1.36 \mathrm{~V}$ & $0.13 \mathrm{~V}$ & $10.6 \%$ \\
\hline
\end{tabular}

